\title{
Premature ventricular contractions originating from the left ventricular septum: Results of Radiofrequency Catheter Ablation in twenty patients
}

$\mathrm{Li} \mathrm{Jia}^{\dagger}$, Li Yue-Chun ${ }^{\dagger}$, Ji Kang-Ting, Zhou Na-Dan, Lin Jia-Xuan, Zhang Wen-Wu, Yang Peng-Lin, Tang Ji-Fei and Lin Jia-Feng ${ }^{*}$

\begin{abstract}
Background: RFCA has been established as an effective and curative therapy for severely symptomatic PVC from the outflow tract in structurally normal hearts. However, it is unknown whether PVCs originating from the left ventricular septum, are effectively eliminated by RFCA. This study aimed to investigate electrophysiologic characteristics and effects of Radiofrequency catheter ablation (RFCA) for patients with symptomatic premature ventricular contraction (PVC) originating from the left ventricular septum without including fascicular PVCs.

Methods: Characteristics of body surface electrocardiogram (ECG) and electrophysiologic recordings endocardiogram in a successful RFCA target were analyzed in 20 patients with symptomatic PVCs originating from the left ventricular septum. RFCA was performed using pace mapping and activation mapping.

Results: The QRS morphology of PVCs originating from the left ventricular septum is similar to that seen in fascicular tachycardia. Most of the PVCs originated from the left septum appears in the form of ventricular parasystole. The incidence of ventricular parasystole was $70 \%$. Sustained ventricular tachycardia was not inducible by electrical stimulation and isoproterenol infusion in all 20 patients, ablation at the site recording the earliest Purkinje potential was not effective in all 20 patients, and Purkinje potentials were not identified at successful sites during point mapping. Sixteen patients were successful with RFCA using pace mapping and activation mapping, 3 failed, and 1 recurrent.

Conclusion: Although the ECG characteristics of the PVCs arising from the left ventricular septum are similar to that seen in fascicular tachycardia, the electrophysiologic characteristics are different between the two types of PVCs. The distinguishing characteristic of the PVCs is that Purkinje potentials were not present at the site of successful ablation, suggesting a myocardial as opposed to fascicular substrate. RFCA is an effective curative therapy for symptomatic PVCs originating from the left ventricular septum (not from the left anterior and posterior fascicle).
\end{abstract}

\section{Background}

Isolated premature ventricular complexes (PVCs) are the most common arrhythmias observed in patients without structural heart disease [1]. In recent years, radiofrequency catheter ablation (RFCA) has proven to be a safe and successful therapy for the arrhythmias [2-5]. PVCs mainly

\footnotetext{
* Correspondence: linjiafeng@medmail.com.cn

† Contributed equally

Department of Cardiology, Second Affiliated Hospital of Wenzhou Medical College, Wenzhou 325000, China
}

originate from the right ventricular outflow tract, with a small part of them originating from the left ventricular outflow tract, mitral and tricuspid valve annulus [6-11]. However, idiopathic PVCs that originated from the left ventricular septum, not involving the left anterior or posterior fascicle, have also been observed. The purpose of this study was to analyze electrophysiological characteristics and the outcome of catheter ablation for such PVCs originating from the left ventricular septum myocardium, without involving the Purkinje-fascicular fibers.

\section{Biomed Central}

(c) 2011 Jia et al; licensee BioMed Central Ltd. This is an Open Access article distributed under the terms of the Creative Commons Attribution License (http://creativecommons.org/licenses/by/2.0), which permits unrestricted use, distribution, and reproduction in any medium, provided the original work is properly cited. 


\section{Methods}

\section{Study population}

From September 2006 to May 2010, a total of 318 patients without structural heart disease were presented for catheter ablation for PVCs in our hospital. Only patients with idopthic PVCs from the left ventricular septum were enrolled in the present study. All patients were verified as having no structural heart disease, including coronary artery disease, valvular heart disease, congenital heart disease, left ventricle hypertrophy, and right ventricle abnormalities by routine biochemistry tests, X-ray, color echocardiography examination, exercise electrocardiogram testing, and/or cardiac catheterization with coronary angiography. Before RFCA, a 12lead ECG was obtained, and 24 hours ambulatory ECG monitoring (Holter) was carried out at least once. The ECG was monitored for 24 hours just before catheter ablation.

\section{Inclusion criteria}

The selection criteria of patients were the following reasons: (1) frequent PVCs occurrence, the average PVC count $\geq 10000$ times/24 h; (2) inability of the patient to tolerate PVCs or unsuccessful treatment with at least two antiarrhythmic drugs; (3) no structural heart disease; and (4) consent for the catheter ablation procedure.

\section{ECG measurements}

Twelve-lead electrocardiograms of the clinical arrhythmia were available for all patients with PVCs originating from the left ventricular septum. The analysis of ECG pattern was focusing on the following characteristics: (1) The QRS morphology of the PVC in all 12 leads, (2) the duration of QRS complex, (3) the axis deviation.

\section{Electrophysiologic study and RFCA}

Electrophysiologic study was performed after withdrawal of all anti-arrhythmic drugs for at least five half-lives. Under fluoroscopic guidance, two quadripolar electrode catheter (Cordis, USA) were advanced from the right femoral vein and positioned in the right ventricular apex and near the His bundle. One additional catheter was inserted via the internal jugular vein and positioned in the coronary sinus. A 12-lead surface electrocardiogram was monitored and recorded on a multichannel oscilloscopic recorder. Programmed electrical stimulation was performed from right ventricular apex at basic drive cycle lengths of 600,500 , and $430 \mathrm{msec}$, delivering a maximum of three extrastimuli. A 7F quadripolar deflectable catheter was advanced into the left ventricle using retrograde aortic approach via the right femoral artery for mapping and ablation (Cordis, USA). The mapping/ablation catheter has a $4 \mathrm{~mm}$ distal electrode, with interelectrode spacing of 2-5-2 mm. Pace mapping and endocardial activation mapping were performed. If the clinical arrhythmia did not occur spontaneously and was not induced in the baseline, intravenous isoproterenol $(2-4 \mu \mathrm{g} / \mathrm{min})$ was administered to induce arrhythmia.

The target site of RFCA was determined by two steps:1) a careful search was firstly performed for Purkinje potentials preceding the onset of QRS during sinus rhythm along the left ventricular septum in all patients, and radiofrequency energy was delivered at sites demonstrating local endocardial recording with earliest presystolic Purkinje potentials during PVCs, or in sinus rhythm if there was insufficient ectopy to permit activation mapping; 2) next step is to obtain the complete or near complete pace mapping with the earliest local activation time if RFCA is not successful, and when the PVC occurred rarely during the electrophysiologic study, only pace mapping was performed, aiming to identify the site where pacing reproduced QRS morphology that is similar to the clinical PVC ( $\geqq 11 / 12$-lead concordance of major and minor deflections). After the target site was located, the energy of RFCA was delivered using maximum power of $40 \mathrm{~W}$, maximum temperature of $60^{\circ}$ $\mathrm{C}$ and impedance of 80-140 $\Omega$ in the temperature-controlled mode. If the PVC was terminated within $10 \mathrm{sec}-$ onds or frequently PVCs and/or nonsustained ventricular tachycardia occurred during ablation at the target site, additional current was applied for another 60 to 180 seconds. Successful ablation was defined as complete elimination of spontaneous or inducible ventricular arrhythmias. Programmed electrical stimulation was repeated at 30 minutes after the last application of radiofrequency energy to confirm the absence of inducible ventricular arrhythmias before removing all catheters and sheaths. If PVC did not terminate within $10 \mathrm{~s}$, the radiofrequency energy application was terminated and another target site was sought.

\section{Definition of successful ablation}

Successful ablation was defined as the absence of spontaneous or induced clinical PVC and ventricular tachycardia, both with or without isoproterenol at the end of the procedure. Absence of PVC or ventricular tachycardia in ECG monitoring over 48 hours without antiarrhythmia drugs. No recurrence of arrhythmia in the absence of anti-arrhythmic drug therapy during followup.

\section{Follow-Up}

After RFCA, all patients underwent 72-hour ECG monitoring. Holter was carried out one week after RFCA. Patients were not given any antiarrhythmic drugs after RFCA, and underwent color echocardiography and 
Holter examination three month after RFCA. ECG echocardiography and 24-hour ECG monitoring were performed whenever the patient had symptoms suggestive of recurrence of ventricular arrhythmias..

\section{Definition of PVC originating from the left ventricular septum}

PVC was considered to originate from the left ventricular septum, not from the left anterior and posterior fascicles, based on (1) the local endocardial recordings; (2) the characteristic of left ventricular septum location and motion (when viewed in the right and left anterior oblique fluoroscopic views after successful RFCA); (3) programmed electrical stimulation could not induce sustained ventricular tachycardia; (4) unsuccessful ablation at Purkinje potential site, and (5) purkinje potentials were not identified at successful sites during point mapping.

\section{Ethics Approval}

Ethical approval was obtained from the Ethics Committee of the Second Affiliated Hospital of Wenzhou Medical College, and all patients gave informed consent before participation in the study.

\section{Results}

\section{Study population}

A total of 20 patients (10 males and 10 females) were enrolled in the present study. Among patients with idiopathic ventricular ectopy, the incidence of left septal ventricular arrhythmias was $6.29 \%$ (Table 1 ). PVCs in 8 of 318 patients originated from fascicles (Table 1 ). The mean PVC burden during the preoperative 24 hours ambulatory Holter monitoring was $17774.05 \pm 5861.66$.

\section{1) Electrophysiologic findings}

PVCs in 20 patients originated from left septum, including 11 from anterosuperior septum, 9 from posteroinferior septum. Table 2 lists the baseline characteristics. The PVC occurred spontaneously in 18 patients and was induced by bolus injection of isoproterenol $(2 \mu \mathrm{g})$ in two patients during the electrophysiologic study. Sustained ventricular tachycardia was not inducible by electrical stimulation and isoproterenol infusion in any patient.

\section{2) Effect of RFCA}

Ablation at the site recording the earliest Purkinje potential was not effective in all 20 patients. By using pace mapping technique and/or activation mapping, RFCA was applied in 20 patients, 17 treatments of which were successful (immediate ablation success rate $85 \%$, Figure 1, Figure 2, Figure 3). Purkinje potentials were not identified at successful sites during point mapping. The local ventricular activation time recorded at successful ablation target sites that preceded the onset
Table 1 PVC origin and results of RFCA for idiopathic ventricular arrhythmias

\begin{tabular}{lll}
\hline Arrhythmia origin & No.(\%) & Success (\%) \\
\hline LV septum & $20(6.29)$ & $16(80.00)$ \\
\hline \multicolumn{1}{c}{ Anterosuperior septum } & $11(3.46)$ & $9(81.82)$ \\
\hline \multicolumn{1}{c}{ Posteroinferior septum } & $9(2.83)$ & $7(77.78)$ \\
\hline Fascicle & $8(2.52)$ & $8(100)$ \\
\hline RVOT & $215(67.61)$ & $204(94.88)$ \\
\hline PA & $11(3.46)$ & $11(100.00)$ \\
\hline Tricuspid annulus & $26(8.18)$ & $23(88.46)$ \\
\hline Aortic sinus of Valsalva & $20(6.29)$ & $15(75.00)$ \\
\hline LVOT & $4(1.26)$ & $4(100.00)$ \\
\hline Mitral annulus & $4(1.26)$ & $4(100.00)$ \\
\hline LV epicardium & $5(1.57)$ & $3(60.00)$ \\
\hline Others (RVIT 3,LV Free wall 3) & $5(1.57)$ & $4(80.00)$ \\
\hline Total & $318(100.00)$ & $351(91.82)$
\end{tabular}

RVOT or LVOT, the right or left ventricular outflow tract, respectively; PA, pulmonary artery; PVCs, premature ventricular complexes; LV, left ventricular; RVIT, right ventricular inflow tract; LV epicardium, Idiopathic ventricular arrhythmias that could not be ablated with RFCA from the left sinus of Valsalva despite earliest ventricular activation being recorded in the left sinus of Valsalva or that could be ablated within coronary venous system were classified as originating from the LV epicardium in the present study.

of the QRS complex was $(31.78 \pm 3.27)$ ms. All pace mappings were perfect $(\geqq 11 / 12)$. Operations came off smoothly with no ablation related complications. Patients have been followed-up for a mean follow-up period of 20.2 months without antiarrhythmic medications. Only one patient had recurrent ventricular arrhythmia at 16 hours after RFCA. The results of RFCA are summarized in Table 3.

3) 12-lead ECG characteristics of PVC originating from the left ventricular septum

The electrocardiographic patterns of PVCs are different at the different sites of origin of left ventricular septum (Table 4). For PVCs originating from left anterosuperior septum, their QRS complex morphology were qR or qRs in leads II, III, aVF, Rs (R/s > 1) in leads V5 V6, $\mathrm{rs}(\mathrm{S})$ in leadsI, aVL and Qr in lead aVR (Figure 4); For PVCs originating from left posteroinferior septum, their QRS complex morphology were $r S$ in leadsII, III, aVF, $R(r) S$ $(\mathrm{R} / \mathrm{S}<1)$ in leads V5 V6, qR(s) in leadsI,aVL and $\mathrm{qR}$ in lead aVR (Figure 5). In 14 of the 20 subjects, the PVCs originating from the left ventricular septum appear in the form of the ventricular parasystolic rhythm (Table 2 ). The incidence rate of ventricular parasystole was $70 \%(14 / 20)$.

\section{Discussion}

The main findings of this study are that PVCs arising from the left ventricular septum can be safely and effectively eliminated with RFCA, the localization of optimal ablation site of the PVCs is different with the typical 
Table 2 Baseline patients characteristics

\begin{tabular}{|c|c|c|c|c|c|c|c|c|c|}
\hline Patient & $\begin{array}{c}\text { Age } \\
\text { (years) }\end{array}$ & Sex & $\begin{array}{c}\text { PVC count } \\
\text { (number } / 24 \mathrm{~h} \text { ) }\end{array}$ & $\begin{array}{l}\text { Number of } \\
\text { AADs used }\end{array}$ & Comorbidities & $\begin{array}{c}\text { LVEF } \\
(\%)\end{array}$ & $\begin{array}{c}\text { Ventricular } \\
\text { parasystolic activity }\end{array}$ & $\begin{array}{c}\text { Origin of PVC } \\
\text { (septum) }\end{array}$ & $\begin{array}{l}\text { RF Lesions prior } \\
\text { to success }\end{array}$ \\
\hline 1 & 14 & $M$ & 23764 & 3 & none & 65 & yes & posteroinferior & 5 \\
\hline 2 & 54 & $M$ & 24316 & 2 & none & 62 & yes & anterosuperior & 3 \\
\hline 3 & 72 & $M$ & 16243 & 2 & none & 62 & no & posteroinferior & 6 \\
\hline 4 & 47 & $\mathrm{~F}$ & 24318 & 2 & none & 68 & yes & anterosuperior & 2 \\
\hline 5 & 65 & $M$ & 11236 & 2 & none & 64 & yes & posteroinferior & 3 \\
\hline 6 & 14 & $M$ & 10243 & 3 & none & 72 & no & anterosuperior & 5 \\
\hline 7 & 76 & M & 16452 & 2 & none & 60 & yes & posteroinferior & 5 \\
\hline 8 & 27 & $F$ & 26742 & 3 & none & 70 & no & anterosuperior & 6 \\
\hline 9 & 24 & $M$ & 18631 & 3 & none & 67 & yes & anterosuperior & 4 \\
\hline 10 & 37 & $F$ & 19632 & 2 & none & 66 & yes & anterosuperior & 3 \\
\hline 11 & 17 & $\mathrm{~F}$ & 12763 & 2 & none & 66 & no & posteroinferior & 4 \\
\hline 12 & 39 & $M$ & 16537 & 2 & none & 63 & yes & posteroinferior & 5 \\
\hline 13 & 45 & $\mathrm{~F}$ & 12344 & 2 & none & 58 & yes & posteroinferior & 3 \\
\hline 14 & 38 & $M$ & 15891 & 2 & none & 61 & yes & anterosuperior & 2 \\
\hline 15 & 48 & $\mathrm{~F}$ & 31463 & 2 & none & 63 & yes & anterosuperior & 2 \\
\hline 16 & 69 & $\mathrm{~F}$ & 15409 & 2 & none & 57 & yes & anterosuperior & 3 \\
\hline 17 & 30 & $F$ & 10858 & 2 & none & 68 & no & anterosuperior & 4 \\
\hline 18 & 28 & $F$ & 11695 & 2 & none & 71 & yes & posteroinferior & 6 \\
\hline 19 & 27 & M & 16932 & 2 & none & 66 & yes & posteroinferior & 3 \\
\hline 20 & 35 & $\mathrm{~F}$ & 20012 & 2 & none & 69 & no & anterosuperior & 2 \\
\hline
\end{tabular}

$\mathrm{AADs}=$ antiarrhythmic drugs, LVEF = left ventricular ejection fraction

location for ectopy originating from the classical fascicular sites. The distinguishing characteristic of this arrhythmia is that Purkinje potentials were not present at the site of successful ablation, suggesting a myocardial as opposed to fascicular substrate. This is the first report that demonstrated that RFCA eliminates PVCs originating from the left ventricular septum (not from classical fascicular sites) by pace mapping and activation mapping, not by searching for Purkinje potential in the left ventricular septum, and found that most cases with the

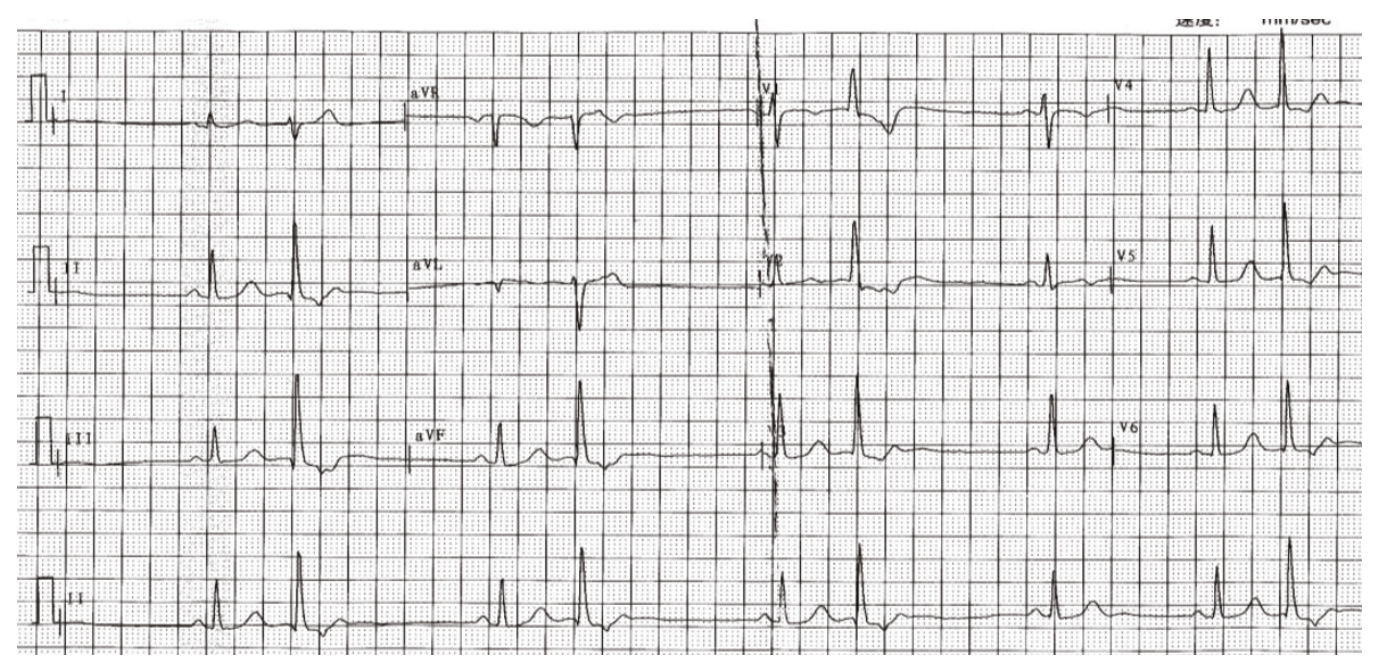

Figure 1 Endocardial recordings of successful ablation target site originating from left anterosuperior septum. The left panel shows that the local ventricular activation time recorded at the ablation site that preceded the onset of the QRS complex was 33 ms and Purkinje potentials were not present at the site of successful ablation. The middle panel shows that pace map at the ablation site provides an identical (12/12) match with the clinical PVC morphology. The right panel shows double potential in front of PVC or VT during ablation ABL, ablation catheter. 

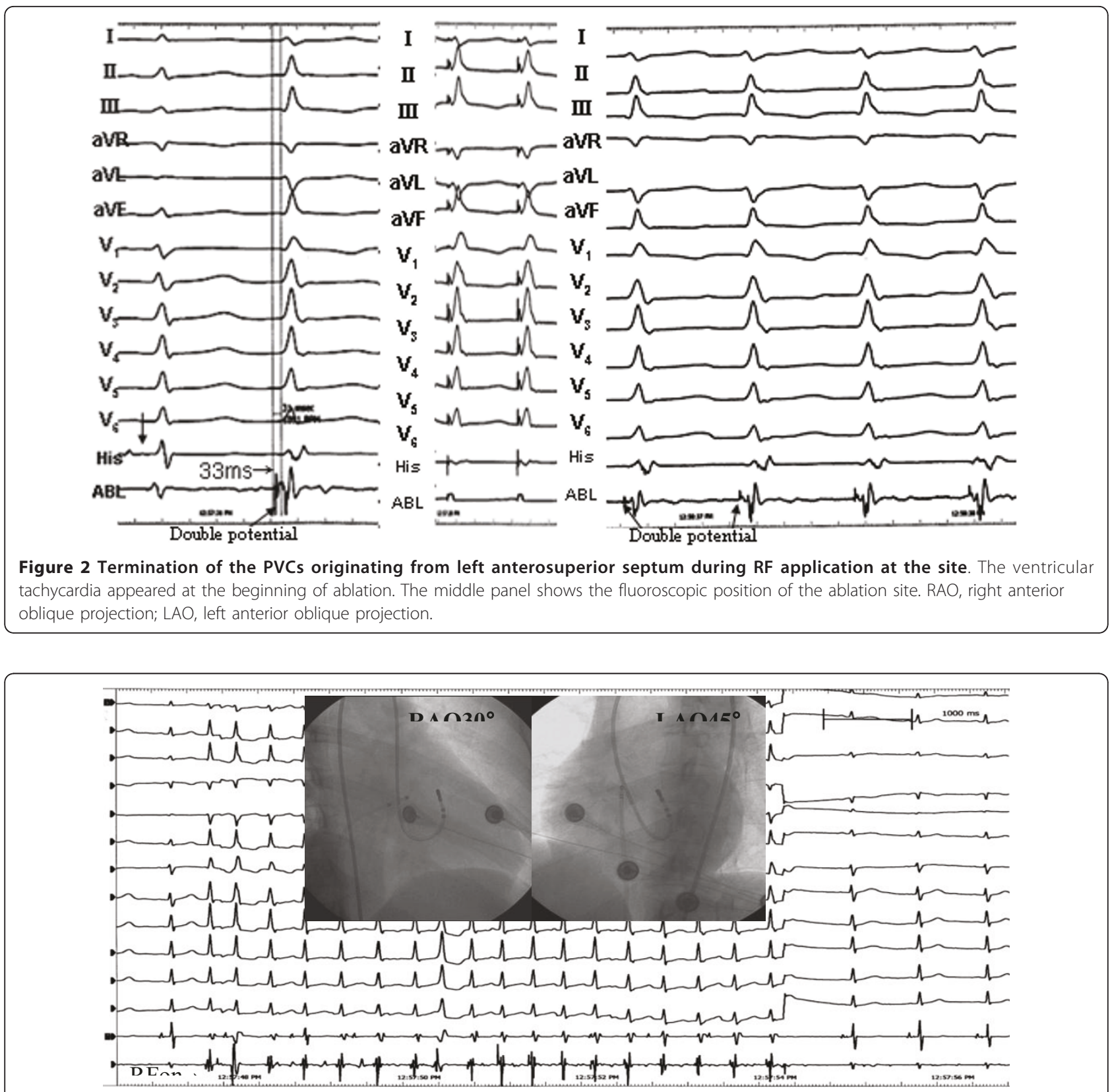

Figure 3 The middle panel show endocardiogram of successful ablation target site originating from left posteroinferior septum. The left panels show ECG during ventricular pacing. The right panels show that the local ventricular activation time recorded at the successful ablation target site that preceded the onset of the QRS complex was 38 ms.

\section{Table 3 The results of RFCA}

\begin{tabular}{|c|c|c|c|}
\hline & $\begin{array}{l}\text { Anterosuperior group } \\
(\mathrm{n}=11)\end{array}$ & $\begin{array}{l}\text { Posteroinferior group } \\
(\mathrm{n}=9)\end{array}$ & *P value \\
\hline Procedure duration (min) & $72.29 \pm 9.71$ & $80.57 \pm 18.32$ & $>0.05$ \\
\hline Radiation exposure time (min) & $13.53 \pm 5.88$ & $14.29 \pm 6.95$ & $>0.05$ \\
\hline Time of the earliest ventricular activation preceding the QRS onset (ms) & $30.80 \pm 3.70$ & $33.20 \pm 2.95$ & $>0.05$ \\
\hline RF lesions prior to success & $3.3 \pm 1.3$ & $4.3 \pm 1.4$ & $>0.05$ \\
\hline Immediate ablation success rate & $81.8 \%$ & $88.9 \%$ & $>0.05$ \\
\hline Recurrent rate (\%) & $0 / 9(0 \%)$ & $1 / 8(12.5 \%)$ & $>0.05$ \\
\hline Follow-up time (month) & $19.43 \pm 15.68$ & $21.14 \pm 16.21$ & $>0.05$ \\
\hline The average cost of ablation per patient (RMB) & $15740.00 \pm 2219.16$ & $16440.00 \pm 2619.16$ & $>0.05$ \\
\hline
\end{tabular}

* P values were compared between the two groups. RMB: Ren Min Bi or China Yuan (China's Currency). 
Table 4 The ECG characteristics of PVCs originating from different sites of origin of left ventricular septum

\begin{tabular}{lcccccccc}
\hline Group & I,aVL & II, III,aVF & aVR & V1 & V2-V4 & V5-V6 & axis & QRS duration \\
\hline anterosuperior & rs or rS & qR or qRs & Qr & rSR or R & qR/R/RS & R or Rs & Right & $99.8 \pm 8.7$ ms \\
\hline posteroinferior & Rs or qR & rS & qR & R & Rs & RS & Left & $116.7 \pm 13.6 \mathrm{~ms}$ \\
\hline
\end{tabular}

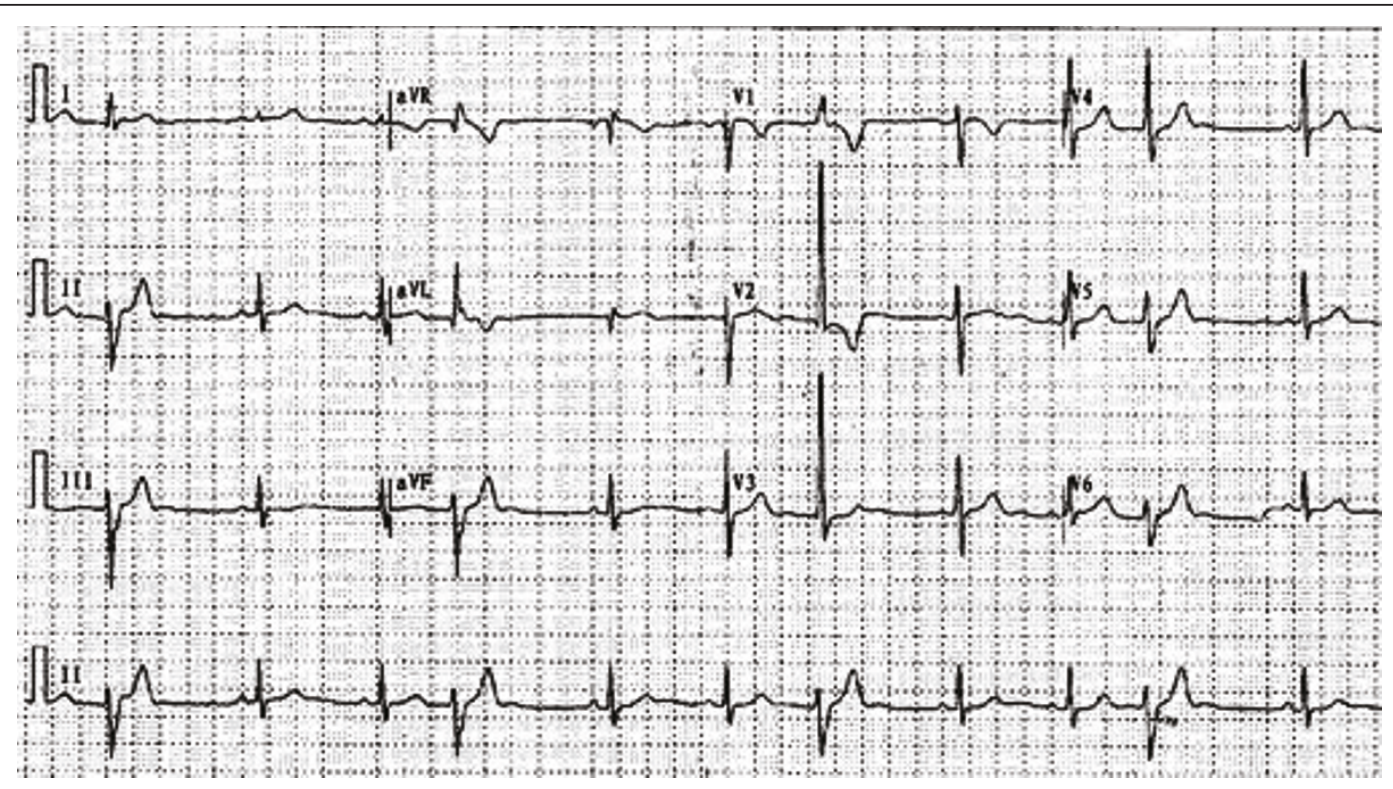

Figure 4 Representative 12-lead ECG characteristics of ventricular arrhythmia originating from left anterosuperior septum.

PVCs arising from the left ventricular septum behaved with parasystolic activity.

In this study, we found that PVCs originating from the left ventricular septum have distinctive ECG characteristics. First, the electrocardiographic patterns are different at the different sites of origin of left septal PVC. For PVCs originating from left anterosuperior septum, their
QRS complex morphology were qR or qRs in leads II, III, aVF, Rs $(\mathrm{R} / \mathrm{s}>1)$ in leads V5 V6, rs $(\mathrm{S})$ in leadsI, aVL and $\mathrm{Qr}$ in lead aVR. For PVCs originating from left posteroinferior septum, their QRS complex morphology were $\mathrm{rS}$ in leads II, III, aVF, $\mathrm{R}(\mathrm{r}) \mathrm{S}(\mathrm{R} / \mathrm{S}<1)$ in leads $\mathrm{V} 5 \sim \mathrm{V} 6, \mathrm{qR}(\mathrm{s})$ in leadsI, aVL and $\mathrm{qR}$ in lead aVR. The QRS morphology of PVCs originating from the left

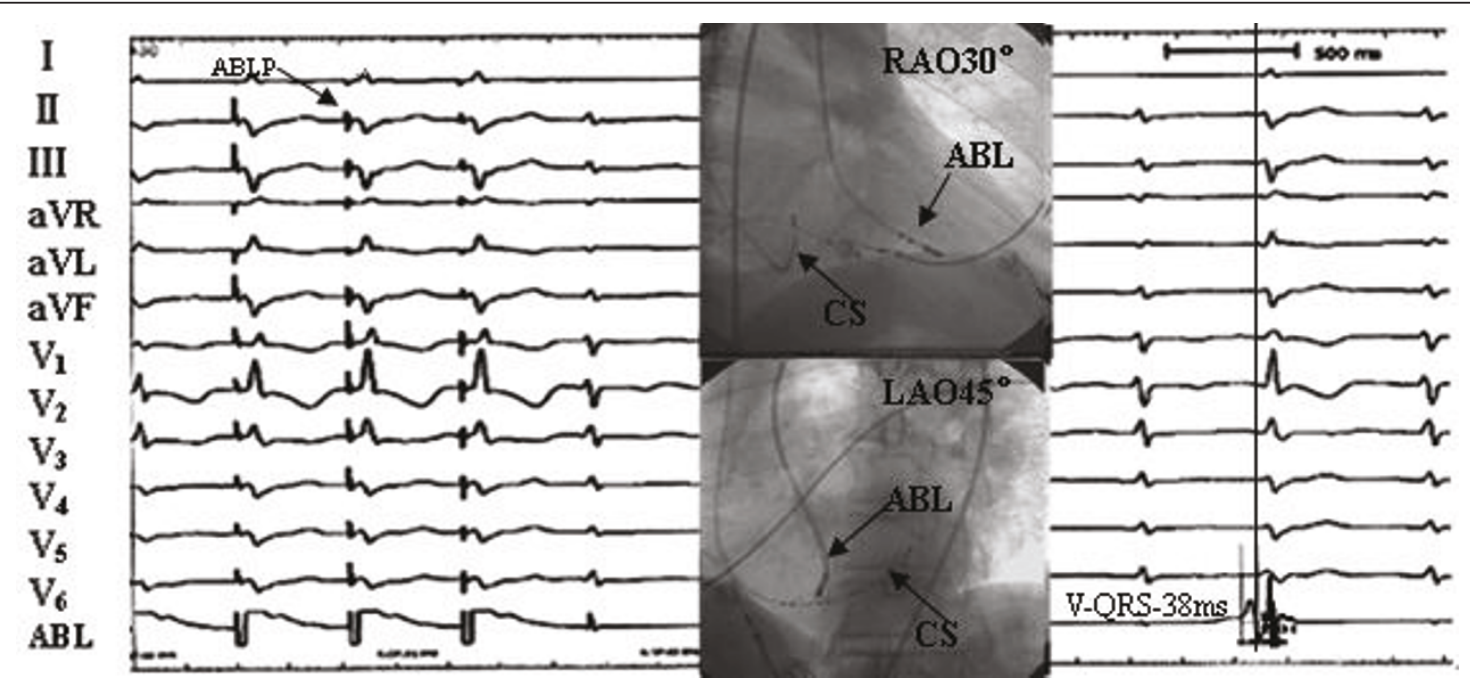

Figure 5 The representative 12-lead ECG characteristics of ventricular arrhythmia originating from left posteroinferior septum. 
ventricular septum is similar to that seen in fascicular tachycardia [12]. Why are there the similarity of the morphology of the premature septal beats and fascicular beats? We suggest that the PVCs may originate from the septal myocardium near by the Purkinje network. Second, most of the PVCs originated from the left septum appear in the form of ventricular parasystole, which is different with fascicular PVCs. In the study, the incidence of ventricular parasystole was $70 \%$. This suggests that the mechanism of the two types of PVCs may be different.

In this study, ventricular parasystole was often observed, sustained ventricular tachycardia was not inducible by electrical stimulation and isoproterenol infusion in all 20 patients, ablation at the site recording the earliest Purkinje potential was not effective in all 20 patients, and Purkinje potentials were not identified at successful sites during point mapping. These suggest enhanced antomaticity, but not reentry as the most likely mechanism of PVCs originating from the left ventricular septum in the study $[13,14]$. The electrophysiologic characteristics of the PVCs originating from the left ventricular septum in the study were different with those from the classical fascicular sites. Therefore, the form of ectopy may occur from the myocardium of the septum, instead of the Purkinje network.

In this study, we demonstrated PVCs arising from the left ventricular anterosuperior and posteroinferior septum can be safely and effectively eliminated with catheter ablation techniques. The immediate ablation success rate was $85 \%$, and the chronic success rate was $80 \%$ (16 of 20 patients) during a mean follow-up period of 20.2 months. One patients experienced significant recurrence of PVCs with associated symptoms. The overall success rate for ablation of PVCs originating from the left ventricular septum in the present study nearly corresponded with the results of previous reports for ablation of PVCs originating from RVOT and/or other sites of origin $[4,15,16]$. The mapping techniques in our study were basically the same as those described in previous studies $[4,5]$, which included pace mapping and activation mapping. No significant complications were observed in our patient group confirming the safety of the procedure.

\section{Study limitations}

First, the mechanism of the PVCs arising from the left ventricular septum is thought to be due to enhanced antomaticity, but not reentry, but this remains speculative in the limited clinical study. Second, although the PVCs may occur from the myocardium of the septum, instead of the Purkinje network, it is unknown that how distributed were these septal sites. To increase the accuracy of our study, our results need to be confirmed in a larger prospective randomized patient population.

\section{Conclusions}

Although the ECG characteristics of the PVCs arising from the left ventricular septum are similar to that seen in fascicular tachycardia, the electrophysiologic characteristics are different between the two types of PVCs. Most cases with the PVCs arising from the left ventricular septum behaved with parasystolic activity. The results of the present study confirm the high success rate and safety of RFCA using conventional techniques in the management of PVCs originating from the left ventricular septum.

\section{Acknowledgements}

This study is supported by Wenzhou Municipal Science and Technology Commission, China (Grant No. Y2008086).

\section{Authors' contributions}

LJF and LYC designed the whole study, LJF, LJ, LYC, JKT, ZND, LJX, ZWW, $Y P L$, and TJF performed the experiment, LF and LYC wrote the paper. All authors read and approved the final manuscript.

\section{Competing interests}

The authors declare that they have no competing interests.

Received: 25 January 2011 Accepted: 2 June 2011

Published: 2 June 2011

\section{References}

1. Wang $K$, Hodges M: The premature ventricular complex as a diagnostic aid. Ann Intern Med 1992, 117:766-770.

2. Bogun F, Crawford T, Reich S, Koelling TM, Armstrong W, Good E: Radiofrequency ablation of frequent, idiopathic premature ventricular complexes: comparison with a control group without intervention. Heart Rhythm 2007, 4:863-867.

3. Krittayaphong R, Sriratanasathavorn C, Dumavibhat C, Pumprueg S, Boonyapisit W, Pooranawattanakul S, Phrudprisan S, Kangkagate C: Electrocardiographic predictors of long-term outcomes after radiofrequency ablation in patients with right-ventricular outflow tract tachycardia. Europace 2006, 8:601-606.

4. Huang CX, Liang JJ, Yang B, Jiang H, Tang QZ, Liu XJ, Wan WG, Jian XL: Quality of Life and Cost for Patients with Premature Ventricular Contractions by Radiofrequency Catheter Ablation. Pacing Clin Electrophysiol 2006, 29:343-350.

5. Takemoto M, Yoshimura H, Ohba Y, Matsumoto Y, Yamamoto U, Mohri M, Yamamoto H, Origuchi H: Radiofrequency Catheter Ablation of Premature Ventricular Complexes From Right Ventricular Outflow Tract Improves Left Ventricular Dilation and Clinical Status in Patients Without Structural Heart Disease. J Am Coll Cardiol 2005, 45:1259-1265.

6. Dixit S, Gerstenfeld EP, Callans DJ, Marchlinski FE: Electrocardiographic patterns of superior right ventricular outflow tract tachycardias: distinguishing septal and free wall. sites of origin. J Cardiovasc Electrophysiol 2003, 14:1-7.

7. Kamakura S, Shimizu W, Matsuo K, Taguchi A, Suyama K, Kurita T, Aihara N, Ohe T, Shimomura K: Localization of optimal ablation site of idiopathic ventricular tachycardia from right and left ventricular outflow tract by body surface ECG. Circulation 1998, 98:1525-1533.

8. Kanagaratnam L, Tomassoni G, Schweikert R, Pavia S, Bash D, Beheiry S, Neibauer M, Saliba W, Chung M, Tchou P, Natale A: Ventricular tachycardias arising from the aortic sinus of Valsalva: an underrecognized variant of left outflow tract ventricular tachycardia. J Am Coll Cardiol 2001, 37:1408-1414.

9. Tada H, Tadokoro K, Ito S, Naito S, Hashimoto T, Kaseno K, Miyaji K, Sugiyasu A, Tsuchiya T, Kutsumi Y, Nogami A, Oshima S, Taniguchi K: Idiopathic ventricular arrhythmias originating from the tricuspid annulus: prevalence, electrocardiographic characteristics,and results of radiofrequency catheter ablation. Heart Rhythm 2007, 4:7-16. 
10. Yamada T, Allison JS, McElderry HT, Doppalapudi H, Epstein AE, Plumb VJ, Kay GN: Successful catheter ablation of premature ventricular contractions originating from the tricuspid annulus using a Halo-type catheter. Europace 2008, 10:1228-1229.

11. Tada H, Ito S, Naito S, Kurosaki K, Kubota S, Sugiyasu A, Miyaji K, Yamada M, Kutsumi Y, Oshima S, Nogami A, Taniguchi K: Idiopathic ventricular arrhythmia arising from the mitral annulus. J Am Coll Cardiol 2005, 45:877-886.

12. Nogami A: Idiopathic left ventricular tachycardia: assessment and treatment. Card Electrophysiol Rev 2002, 6:448-457.

13. Nakagawa H, Beckman KJ, McClelland JH, Wang X, Arruda M, Santoro I, Hazlitt HA, Abdalla I, Singh A, Gossinger H: Radiofrequency catheter ablation of idiopathic left ventricular tachycardia guided by a Purkinje potential. Circulation 1993, 88:2607-2617.

14. Kuo CS, Surawicz B: Coexistence of ventricular parasystole and ventricular couplets: Mechanism and clinical significance. Am J Cardiol 1979, 44:435-441.

15. Klein LS, Shih HT, Hackett FK, Zipes DP, Miles WM: Radiofrequency catheter ablation of ventricular tachycardia in patients without structural heart disease. Circulation 1992, 85:1666-1674.

16. Coggins DL, Lee RJ, Sweeney J, Chein WW, Hare GV, Epstein L, Gonzalez R, Griffin JC, Lesh MD, Scheinman MM: Radiofrequency catheter ablation as a cure for idiopathic tachycardia of both left and right ventricular origin. J Am Coll Cardiol 1994, 3:1333-1341

\section{Pre-publication history}

The pre-publication history for this paper can be accessed here: http://www.biomedcentral.com/1471-2261/11/27/prepub

doi:10.1186/1471-2261-11-27

Cite this article as: Jia et al: Premature ventricular contractions originating from the left ventricular septum: Results of Radiofrequency Catheter Ablation in twenty patients. BMC Cardiovascular Disorders 2011 11:27.

\section{Submit your next manuscript to BioMed Central and take full advantage of:}

- Convenient online submission

- Thorough peer review

- No space constraints or color figure charges

- Immediate publication on acceptance

- Inclusion in PubMed, CAS, Scopus and Google Scholar

- Research which is freely available for redistribution

Submit your manuscript at www.biomedcentral.com/submit 